\title{
Esperando a E. P. Thompson. Desindustrialización y formación de clases sociales en Argentina (1976-2001)
}

\section{Juan Grigera*}

Resumen: Este trabajo señala el silencio existente en las ciencias sociales (incluyendo al marxismo) en Argentina respecto de una reflexión y debates sistemáticos sobre los modos en que se forman las clases sociales, particularmente la clase obrera, de la dialéctica entre las transformaciones en la industrialización y la lucha de clases. En primer lugar se recorre una serie de ejemplos significativos de la literatura para mostrar que la reflexión sobre este problema es mecánica o notoriamente escasa, aún cuando constituye un núcleo fundamental de esos trabajos. Luego el artículo muestra la centralidad de este problema partiendo de las nociones de clase en Marx para concluir que la obra clásica de E. P. Thompson, La Formación de la clase obrera en Inglaterra, aún no ha tenido el impacto que su reflexión central merece en Argentina.

Palabras clave: Desindustrialización - Lucha de clases - experiencia en E. P. Thompson

Abstract: This paper shows the presence of a silence in Argentinean social sciences (including Marxism) regarding systematic reflection and discussion on the ways in which social classes are formed, particularly the working class, and on the dialectic between changes in industrialization and class struggle. First, through a series of significant examples we show that so far the reflection on this problem has been mechanical or notoriously poor, even in cases where this was supposed to be the core of the publications. Then the article illustrates the centrality of this issue based on the notions of class in Marx and concludes that the central issue of $E$. P. Thompson's classic work The Formation of the English Working Class has not yet had the impact it deserves in Argentina.

Keywords: Deindustrialization - Class struggle - experience in E. P. Thompson

* Doctor por la Universidad de Buenos Aires (UBA) y Magister en Development Studies por la London School of Economics (LSE). Es Profesor Adjunto de Historia del Pensamiento Económico e Introducción a la Economía en la Universidad Nacional de Quilmes y de Problemas de Historia Argentina en la Facultad de Humanidades y Ciencias de la Educación de la Universidad Nacional de La Plata y Becario Postdoctoral de CONICET. 


\section{Introducción}

El núcleo central de La Formación de la clase obrera en Inglaterra y de buena parte de la obra de E. P. Thompson ha sido articular de modo relevante una reflexión sobre las formas en que se articulan las formas de la lucha de clases y las transformaciones en los modos de acumulación de capital. Sin embargo, mostraremos en este artículo que esta reflexión no ha tenido en Argentina el lugar que su importancia teórica y política merece.

En primer lugar analizaremos los estudios sobre la historia argentina reciente (el último cuarto del siglo XX), por su importancia en términos de las transformaciones operadas tanto en la acumulación de capital (por ejemplo, la llamada desindustrialización) como en las formas de conflicto social. Vamos a mostrar como se produce un hecho sorprendente. Por un lado una muy extensa literatura que da cuenta de las transformaciones en las organizaciones del movimiento obrero y la creciente importancia de otras formas de conflictividad como los movimientos sociales se halla prácticamente desvinculada de otro terreno de debates sobre las profundas transformaciones en los modos de acumulación de capital y el profundo proceso de cambio industrial. Es decir, pareciera extenderse un perturbador silencio en torno de la reflexión (marxista y no marxista) sobre la relación entre conflicto social/lucha de clases y transformaciones en la estructura económica, procesos de industrialización, patrones de acumulación de capital. En este sentido este trabajo se pregunta: ¿podemos identificar un cuerpo de reflexión teórica sobre este problema o más bien solo una nube de reflexiones ad-hoc?

Luego este trabajo argumenta que el núcleo de la cuestión que identificamos, lejos de ser un tópico inaugurado por E. P. Thompson, es un problema que lo precede, que está imbricado en la propia concepción de clase social desde Marx. Mostraremos que Thompson es relevante en tanto aporta una de las pocas aproximaciones hacia una solución de este problema.

Finalmente, vamos a señalar que este problema teórico no ha tenido demasiado impacto en la recepción marxista de Thompson en Argentina y que el problema fundamental de pensar qué tipo de consecuencias implican las transformaciones en la estructura de las relaciones sociales de producción sobre las posibilidades y la dinámica concreta del conflicto de clase prácticamente no ha sido abordado en los últimos treinta años.

Este trabajo concluye destacando la importancia teórica y política de pensar esta dimensión y enfatizando por tanto la gravedad de este silencio. En suma, señalamos esa ausencia y reseñamos la fragilidad del fantasma que suplanta una reflexión sistemática invitando a la apertura del necesario debate retomando de este modo un aspecto fundamental de E. P. Thompson.

\section{Desindustrialización y lucha de clases (1976-2001)}

Las enormes transformaciones que han sacudido a la sociedad argentina y a sus pares latinoamericanas desde mediados de la década de 1970 involucran, sin duda, tanto al terreno de las formas del conflicto de clases (dicho sucintamente los enormes cambios en el movimiento obrero desde su derrota estratégica vehiculizada a sangre y fuego por la dictadura militar hasta sus nuevas formas de organización como piqueteros) como a los patrones de acumulación de capital (la 
Ilamada desindustrialización, la tercerización, los cambios en las formas de producción). Es lícito preguntarse por tanto, cuál ha sido la reflexión teórica e histórica sobre la dinámica de estos cambios desde un ángulo particular, esto es ¿Cómo se ha teorizado la relación entre ambos procesos, particularmente el impacto de las transformaciones en los patrones de acumulación de capital sobre las formas de lucha y resistencia del movimiento obrero? ¿Qué adscripciones teóricas más amplias han reconocido estas reflexiones? ¿Son consistentes con el resto de los trabajos o se deslizan consensos silenciosos entre distintas corrientes teóricas?

La primera constatación ante esta pregunta crucial es sorprendente. A pesar de su importancia, el tema no ha sido tratado autónomamente, ni ha dado lugar a polémicas específicas (como podría esperarse, ni al interior del marxismo ni entre marxistas y otras corrientes teóricas que intentan pensar cuál es la relación entre proceso de industrialización y conflicto social). Mas bien, lo que podemos encontrar para reseñar es un conjunto de reflexiones dentro de límites estrechos. Aún ampliando la pregunta a todo el siglo XX, la producción argentina en este terreno es mínima. Por ejemplo, si bien el debate en torno a los orígenes del peronismo incorpora en su agenda (aunque de un modo particular), desde la primer intervención de Gino Germani, la problemática de la "modernización” y las transformaciones debidas a los "migrantes internos", a lo largo de su desarrollo ninguna posición critica la forma (mecánica) en que se concibe esta relación. La polémica en general se concentra en la búsqueda de otra evidencia empírica o en la incorporación de otros fenómenos explicativos, acordando implícitamente con la formulación teórica de Germani.

En el período que nos proponemos analizar existen dos usos distintos de algunos de estos modelos de vinculación entre modelo de acumulación y formación de la clase obrera como sujeto político: el impacto de los cambios en la política de los '80 y de los años '90 y entre ambas décadas. Para acotar la exposición de este problema, tomaré unos pocos textos significativos en cada uno de estos dos casos.

El primero se refiere a aquellos textos que dan cuenta de la derrota que sufrió la clase obrera durante el golpe militar de 1976. La derrota estará signada por los efectos represivos de la dictadura burguesa, aunque no sólo por estos. Lejos de tener un efecto coyuntural, su verdadera profundidad se pondrá de manifiesto durante la llamada "transición democrática", en la incapacidad de recuperar los niveles de participación en la vida política previos al golpe. Es decir, a la incapacidad de rearticular un movimiento obrero homogéneo alrededor de sus organizaciones sindicales, capaces de defender corporativamente sus intereses o de proyectarse políticamente.

En un segundo momento nos referiremos a las formas de lucha y resistencia de la clase durante el menemismo, en un ciclo que concluye hacia el 2001. El grupo de análisis que se refiere a este período suele desprenderse de la consideración del período antes mencionado y hacer hincapié en la emergencia de los así llamados "movimientos sociales".

\section{La Desindustrialización y la derrota (1976-1983)}

Una de las contadas reflexiones sobre el impacto de las transformaciones

"económicas" de la dictadura militar sobre las formas de organización de la clase 
obrera es el trabajo de Juan Villarreal en 1985. Villarreal caracteriza al período previo a la dictadura de 1976 como "homogéneo por abajo y heterogéneo por arriba". Entiende que la amplia difusión de la relación salarial, el peso mayoritario de los trabajadores industriales y la homogeneidad de los puestos de trabajo (ingresos) configuraron en torno al peronismo "condiciones homogeneizantes en un proceso de formación de clases". En otras palabras, la clase obrera se constituyó como sujeto político en Argentina en el peronismo y de alguna manera esta constitución quedó atada a las condiciones de desarrollo bajo el "modelo de industrialización por sustitución de importaciones (ISI)". Por otra parte, en el mismo período la heterogeneidad de "los que mandan" era el resultado de un perfil estructural particular de Argentina: escasa centralización del capital, diversificación productiva etc.

Para Villarreal el golpe militar viene a revertir esta situación en una doble operación. De una parte, implementa políticas de "homogeneización por arriba" (concentración, hegemonía, representación), y por otra de "heterogeneización por abajo", es decir, de desarticulación de las organizaciones de clase, es decir, según lo dicho anteriormente, de la clase en tanto sujeto estructurado en torno al peronismo. ¿De qué manera? La dictadura "implementa la desindustrialización" para reducir el peso de los obreros industriales, favorece el crecimiento del cuentapropismo y la tercerización (restando peso al obrero por sobre el empleado), incentiva la estratificación salarial y destruye los lazos de solidaridad mediante la represión y el terror.

Estos "efectos de poder" consistentes en "destruir, golpear o dividir a sus enemigos: los sectores populares" constituyen en definitiva los "objetivos latentes" del proceso. La desindustrialización resta peso relativo a industriales medios y obreros manufactureros al mismo tiempo, desmontando el "eje de la alianza industrial-obrera" que supuestamente articulaba al peronismo. La caída del salario real y del empleo industrial implica, además de distintos apremios económicos para trabajadoras y trabajadores, un obstáculo para el financiamiento de las propias organizaciones políticas. El crecimiento de la cantidad de empleados (entiéndase asalariados en el sector servicios) que "desplazan a los obreros como mayoría", implica para Villareal el crecimiento de un sector con "escasa combatividad, limitada tradición de lucha y falta de cohesión [...] derivado de pertenecer a un mosaico heterogéneo de actividades laborales." Por último, el crecimiento de los trabajadores independientes reduce el peso de los asalariados:

Una política desindustrializadora que expulsa trabajadores del campo de la producción, una caída de los niveles salariales masivos que desalienta el trabajo asalariado y un endurecimiento de las condiciones de trabajo en relación de dependencia que estimula la búsqueda de la ocupación por cuenta propia. ${ }^{2}$

Villarreal entiende que los empleados son "una nueva fracción del proletariado", que por no estar ligados a la producción material como los obreros, son un sector social postergado, severamente explotado, bajos salarios, descalificados en el proceso de trabajo etc. Pero también sostiene que su lucha sindical se "inscribe directamente en el terreno del ejercicio del poder y se vuelve inmediatamente lucha política." ¿Por qué entonces se encuentran "rezagados en relación con el nivel

1 VILLARREAL, Juan. 'Los hilos sociales del poder’. En: JOZAMI, E. (Ed.). Crisis de la dictadura argentina. Buenos Aires: Siglo XXI, 1985, p. 201-68.

2 Ibidem, p.259. 
de lucha, organización y conciencia de los obreros"? Villarreal sugiere que esto responde a su diseminación en pequeños talleres o establecimientos, un conjunto difuso de factores ideológicos que incluyen "una escasa memoria de tradiciones propias de lucha y organización." Finalmente, pese a este panorama desalentador, el texto cierra con una perspectiva optimista, avanzando la hipótesis según la cual por fuera de las limitaciones políticas de los empleados "su peso social crecientemente mayoritario es probable que los conduzca a ocupar un lugar cada vez más destacado en la vida política". 3

Si Villarreal se inscribe como uno de los pocos textos que intentan articular esta reflexión, es Francisco Delich quien más tempranamente postula la idea de derrota del movimiento obrero e intenta radicar una parte de este fenómeno en las transformaciones económicas del período. ${ }^{4}$

Delich nos propone analizar la acción coyuntural en una perspectiva de largo plazo, que tenga en cuenta también la configuración y cambios de una variable que propone como fundamental y nombra como "memoria de clase". Esta memoria de clase "no coincide sincrónicamente con su composición," sino que sufriría los cambios con cierta inercia. Como ejemplo de una visión sincrónica, Delich cita el debate sobre los orígenes del peronismo y a Germani, para mencionar, por ejemplo, que el recambio cualitativo de artesanos por peones industriales sin calificación como la pérdida de hegemonía de los sindicatos de la carne y textiles en favor de metalúrgicos y electricistas tiene una dinámica y un impacto no inmediato sobre la "memoria de clase". Esta memoria, podemos aventurar, es una suerte de composición de clase con historia. ${ }^{5}$

La formación de la clase obrera como sujeto en Argentina para Delich se da en la congruencia de cierto modelo sindical, un modelo de desarrollo industrial por sustitución de importaciones (ISI), una fracción industrial de la burguesía y un tipo de Estado. Este entramado culmina en el punto máximo de poder "corporativo-sindical" en el período 1973-76. Es entonces este conjunto de dimensiones las que entran en crisis a partir de 1976, señalando tempranamente que la reestructuración capitalista tendría efectos más duraderos sobre la formación de la clase obrera que el inmovilismo de la organización sindical que podría explicarse coyunturalmente por los atroces niveles de represión. ${ }^{6}$

Delich describe la situación de la clase obrera a la salida de la dictadura con los siguientes índices: caída del salario real, reducción de doscientos mil puestos de trabajo en el Estado (aunque sin desocupación abierta), la suspensión de las convenciones colectivas de trabajo, la intervención de la CGT y la ley de Asociaciones Gremiales de 1979:

3 VILLARREAL, op. cit., p.269.

4 DELICH, Francisco. "Después del diluvio, la clase obrera". En: ROUQUIÉ, A. (Ed.). Argentina, hoy. Buenos Aires: Siglo XXI, 1982, 129-50.

5 La referencia a composición de clase es en un contexto puramente estructural y no guarda relación con el concepto de composición del operaismo italiano.

6 DELICH, Francisco. “Desmovilización social, reestructuración obrera. y cambio sindical”. Critica y Utopía. 6 , p. 79-97, 1981. 
La clase obrera perdió salarios y empleo. Perdió sus sindicatos. Perdió sus obras sociales. Perdió las convenciones colectivas. Por si todo esto fuera poco se resquebrajó la solidaridad que estaba (y está) en el fundamento de cualquier acción colectiva.7

Estas sin embargo son perdidas políticas que podrían recuperarse, pero Delich analiza en un orden más general, el impacto de la reestructuración: la clausura del modelo de sustitución de importaciones y la respuesta sindical al mismo. Aquí, Delich menciona dos "nuevos desafíos para las formas de acción obrera". El primero es la tendencia sostenida (desde 1950) y peculiar en Argentina de crecimiento del sector no asalariado. El segundo es la consecuencia de la suspensión de los convenios colectivos, el instrumento que "igualando las demandas y expectativas individuales conformaba una base social que se reconocía como conjunto y en consecuencia cobraba una fuerza formidable" (es decir, el instrumento que servía para constituir a la clase obrera como sujeto político). Delich sostiene que la pérdida de este instrumento conllevó una alta "dispersión salarial" y a la disolución de esta base social, ambos efectos buscados por el plan económico de la dictadura: "Si el conjunto de la clase obrera fue agredido por la política salarial, no es menos cierto que sectores obreros calificados fueron beneficiados." 8 La dispersión salarial es, para Delich, uno de los nuevos desafíos que deberá enfrentar la clase obrera después de la dictadura.

¿Cuáles son los elementos relevantes de estas lecturas (representativas de un amplio espectro académico y político) para pensar la relación entre desindustrialización y transformaciones en las formas de lucha de la clase obrera? Dejaremos de lado para esto cualquier objeción empírica para concentrarnos en la manera en que plantean la relación entre "el plan económico" y las dificultades políticas de la clase obrera post-dictadura. ${ }^{9}$

En primer lugar debe destacarse que estas reflexiones (escritas entre 1981 y 1983) han resultado notoriamente más relevantes y profundas en su análisis, en tanto reconocen y predicen el impacto duradero de la reestructuración capitalista del período sobre las formas de lucha de clases, que aquellos inspirados en análisis institucionales o coyunturales. Estos últimos esperaban una "revolución democrática" o un punto de inflexión en el fin de la dictadura y una "transición hacia la democracia" con un rol activo de la clase obrera o la "ciudadanía". Podemos entonces destacar la potencia de estas consideraciones estructurales sobre las condiciones en que se desenvuelve la lucha de clases para el análisis político.

Sin embargo, es necesario señalar algunos elementos donde los análisis resultan notoriamente insuficientes. En primer lugar en la forma de concebir el proceso de desindustrialización como una respuesta de la burguesía (o de alguna fracción

7 Idem. "Pacto corporativo, democracia y clase obrera". Critica y Utopía. 7, 1982.

8 Idem. op. cit., 1982, p.149.

9 Aún cuando parte de la evidencia es ciertamente dudosa. A titulo de ejemplo, Villarreal sostiene la existencia de desindustrialización aportando por único dato una caída del 3.2\% del PBI del producto manufacturero en el período (dato que de un cuadro en la p. 248 se redondea al $4 \%$ en el texto en p. 277 ). 0 entiende un cambio cualitativo entre 1976 y 1980 hacia un "peso económico considerable" de la categoría de "empleados" cuando el porcentaje de la PEA que reviste esta categoría pasa del 50\% en 1970 a 52\% en 1980 (p. 255). Asimismo, la doble operación de homogeneización por arriba y heteroneneización por abajo tiene un sujeto difuso, por fuera de y sobre las clases sociales. 
de la misma), como un plan deliberado con el objetivo de debilitar la constitución de la clase obrera como sujeto político. Esta tesis encierra un razonamiento falaz en doble sentido, que además ha ganado notorio consenso en el sentido común crítico argentino y que puede formularse sucintamente del siguiente modo: la dictadura vino a desindustrializar para acabar con la importancia de la clase obrera. La falacia incluye asumir que se trata de un proceso voluntario, que existe una relación lineal entre poder de la clase obrera (de la que "empleados en servicios" parecen no formar parte) e industria. Pero por sobre todo, el razonamiento entiende que el Estado es entonces capaz de encarar una agresión sistemática al sector hegemónico (la industria es descripta como el "articulador de las relaciones socioeconómicas”), lo que sería algo así como dispararse en el pie. En otras palabras, la dictadura desindustrializó, “destruyó la industria”, para “desperonizar” o para minar el poder obrero. La lógica de esta argumentación es equivalente a sostener que la burguesía, para acabar con el poder sindical, puede erradicar el trabajo, o que, para acabar con la lucha de clases, puede decidir, voluntariamente, autodisolverse. ${ }^{10}$

En segundo lugar, es notorio destacar el prejuicio que destilan los textos respecto de la organización obrera en el contexto del trabajo en servicios. Productos históricos los mismos textos analizados, éstos naturalizan algunas condiciones históricas como regularidades invariables. Por ejemplo, la caracterización de Villarreal de "empleados" ha mostrado su cara reversa en las décadas siguientes: en los años '9o cuando fueron justamente estatales y desocupados los que mostraron más altos niveles de combatividad y organización, o en la posconvertibilidad, cuando sindicatos como los camioneros o los trabajadores de subterráneos mostraron la importancia de sus posiciones estratégicas en la producción. Es decir, algunas de las condiciones que parecían prima facie "estructurales" (el tamaño de los establecimientos, la diversidad de sus tareas) no resultaron determinantes a la hora de la (re)estructuración de la formación de clase. ${ }^{11}$

Los prejuicios sobre la posición estratégica de las y los trabajadores de servicios también son interesantes de destacar. En el corto plazo, de hecho, podría argumentarse que los servicios son más vulnerables a las huelgas (en tanto no hay stock como en los sectores manufactureros). Una mirada al famoso Plan Ridley con que Margaret Thatcher decidió encarar la huelga de los mineros lista entre las ramas de mayor vulnerabilidad a huelgas (según el informe aquellas "sin las cuales la nación no puede sobrevivir ni una semana”): servicio de agua y cloacas, servicio de electricidad, servicio de gas, servicio de salud (NHS), mientras que la minería especula que puede tolerarse por cuatro semanas y el acero "por un largo tiempo". ${ }^{2}$

En el mismo orden, aún cuando es menos estructural, la dimensión histórica de nociones como movimiento obrero "homogéneo" / "heterogéneo" debe ser puesta en consideración. ¿En torno a qué características se homogeniza el movimiento obrero? Es decir, es necesario historizar los elementos aglutinadores e igualadores de los sujetos antes que asumir que determinadas características son

10 En otros trabajos hemos desarrollado esta crítica al modo en que se reflexiona sobre la desindustrialización en la literatura argentina. Puede consultarse GRIGERA, Juan. "Desindustrialización, ¿agresión a la manufactura o reestructuración capitalista?". Em: BONNET, A. (Ed.). El país invisible. Debates sobre la Argentina Reciente. Buenos Aires: Peña Lillo / Ediciones Continente, 2011, p. 81-101; Idem. "El concepto de desindustrialización como peculiaridad argentina”. Revista de Estudios Marítimos y Sociales. 5, 2012.

11 Posiblemente algunos de los factores aludidos deban reconsiderarse específicamente. Por ejemplo, tal vez sea falsa la correlación "empleados"|“"pequeños establecimientos” y no la correlación "dificultad para estructurar organizaciones de clase"|"pequeños establecimientos".

12 Informe Ridley "Report of Nationalised Industries Policy Group (leaked Ridley report)". The Economist. Mayo 1978. 
universalmente "homogeneizadoras". Por ejemplo, el salario uniforme y de convenio no necesariamente es un elemento de unificación, aunque sí se halla convertido en tal bajo determinadas situaciones históricas y su dispersión se convierta en una derrota. En otras palabras: determinadas "heterogeneidades" no son por si mismas signo de debilidad, ni condicionantes estructurales de una debilidad, puede que lo sean únicamente en función de una construcción histórica previa que así las constituyó.

Finalmente, es posible proponer como hipótesis que el proceso descripto de descomposición de la clase obrera mediante una brutal reestructuración capitalista en todos los niveles (es decir, no solo una reestructuración de las bases materiales, pero sí esta como signo de su profundidad) implica una posterior re-estructuración de la clase obrera, una re-formación de nuevas respuestas, tipos y organizaciones de la clase como sujeto político. Tanto Delich como Villarreal reconocen y advierten sobre "la derrota", sobre las dificultades que conllevará construir una nueva "memoria de clase", o re-estructurar la "experiencia" en el sentido de Thompson. Por momentos, los autores pierden de vista que la relación proceso de industrialización y formación de clase es aquella que conocemos como producto del resultado histórico, pero que no es única. Volveremos sobre estas conclusiones parciales.

\section{De la derrota de la clase a la derrota electoral peronista}

El segundo proceso que ha llevado a algún tipo de reflexión sobre la relación entre ambos procesos es el de la transformación del partido peronista en las décadas de 1980 y 1990. Uno de los trabajos más representativos en este sentido es el de Steven Levitsky, quien documenta extensamente cómo el aparato del Partido Justicialista (PJ, el partido peronista) está altamente controlado, financiado y constituido por las distintas burocracias sindicales hacia el fin del proceso dictatorial. ${ }^{13}$ Tanto la composición de las listas como la campaña y las negociaciones estuvieron en manos de representantes sindicales, hasta consagrar formalmente el poder de facto de este sector en el congreso del partido de 1983 en que Lorenzo Miguel, secretario general de la Unión Obrera Metalúrgica, fue nombrado presidente. Desde entonces, hasta los años '90

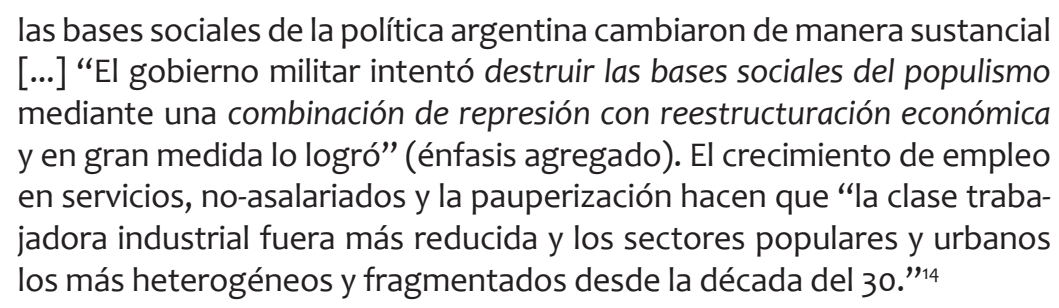

La desindustrialización impacta sobre la conformación del Partido Justicialista de dos maneras. En primer lugar, demoliendo las bases sociales de los sindicatos industriales, quienes vieron disminuir la cantidad de afiliados y por tanto su peso

13 LEVITZSKY, Steven. La transformación del justicialismo: del partido sindical al partido clientelista, 19831999. Trad. Leandro Wolfson, Buenos Aires: Siglo XXI, 2005.

14 Ibidem, p.130. 
político y económico. ${ }^{15}$ Esto significó un cambio en la relación histórica del peronismo con los sindicatos industriales, aunque Levitsky agrega

la naturaleza descentralizada del trabajo en muchas actividades de venta minorista y de servicios hizo que algunos sindicatos como el de los empleados de comercio, el de los gastronómicos, el de los encargados de edificios, el de los árbitros deportivos y el de los agentes de seguridad privados tuvieran escasa capacidad movilizadora, se comprometieran poco con la acción colectiva y tendieran a no forjar identidades colectivas sólidas. ${ }^{16}$

En nota al pie exceptúa de esta regla a bancarios y estatales.

En segundo lugar, para Levitsky, la desindustrialización pone en peligro la base electoral tradicional del PJ. "El declive de la clase obrera industrial creó dos nuevos grupos de votantes: los 'nuevos pobres urbanos', cuya base era el sector urbano informal, y la 'nueva clase media', basada en el sector de venta minorista y de servicios." ${ }_{17}$ Si el salto suena un tanto abrupto entre empleo y grupos de votantes, Levitsky acerca el siguiente vínculo:

Los trabajadores del sector informal suelen ser más pobres que los trabajadores manuales, pero la naturaleza heterogénea y geográficamente dispersa de su trabajo debilita su identidad colectiva y crea "intereses objetivos difíciles de articular con los de los asalariados". ${ }^{18}$

Por esto era "muy improbable" que estos sectores se mantuvieran ligados al peronismo a diferencia de los sindicales obreros. El PJ, por lo tanto, abandona su tradicional base sindical y reformula los vínculos con los sectores populares por via del clientelismo.

Si bien este es el núcleo del argumento, debemos retomar la línea de reflexión que nos interesa. En este caso son dos los elementos que caracterizan las reflexiones sobre la relación entre formación de clase y desindustrialización y que en lo fundamental reiteran las reflexiones anteriores. De una parte, el reconocimiento de un entramado histórico que por el solo hecho de ser alterado (reestructuración capitalista) da lugar a una reestructuración de las formas de organización política, en este caso, de la vinculación de un partido político con su base obrera. Por otra, en este contexto se repite también la naturalización de una forma histórica de esta relación: en la supuesta correlación entre categorías de empleo y tipos de votantes, en la naturaleza heterogénea y débil del sector informal, en la escasa combatividad de los sectores de servicios.

\section{Los '90: ¿adiós a la clase?}

La literatura sobre la "protesta social" en Argentina se ha desarrollado bajo el impulso hegemónico de la literatura de la acción colectiva. Esta teoría de "ran-

\footnotetext{
15 Las cifras sin embargo hablan de caída absoluta de afiliación, pero la relación causal con la caída del empleo industrial es más dudosa. A simple vista la desafiliación es más importante que la caída del empleo industrial (la afiliación cae entre un 50\% y un 70\% mientras que el empleo industrial según estas mismas cifras cayó un 26\%). Ibidem, p.129.

16 Ibidem. (énfasis añadido)

17 LEVITSKY, Steven, op. cit., p.132.

18 Ibidem, p.132. (énfasis añadido)
} 
go medio" propone articular cambios "macro-estructurales" y "micro-procesos", como el desarrollo del capitalismo y las relaciones "estado-ciudadanos" en la consideración de como las grandes transformaciones dan forma a la acción colectiva de manera indirecta, "al afectar intereses, oportunidades, organizaciones e identidades de la gente común". ${ }^{9}$ Rescata a su vez una dimensión política, insistiendo que no hay un vínculo directo entre "penurias" o "problemas sociales" y acción colectiva y una dimensión "cultural”, los repertorios "son creaciones culturales aprendidas". La multiplicidad de trabajos producidos bajo esta influencia hace más difícil ilustrar el modo de reflexión sobre el problema que nos ocupa en un espacio breve. Pero aún a riesgo de cometer alguna injusticia tomaremos un caso representativo, un trabajo de Javier Auyero, para ilustrar el modo en que se articuló esta reflexión.

Auyero sostiene que la teoría de la "acción colectiva" nos invita a pensar "el impacto que tiene el cambio estructural en la protesta y los cambios en la cultura de la lucha popular". 20 Su caracterización de la "insurgencia popular argentina" comienza por los siguientes hechos relevantes a los que "debemos prestar atención" en forma simultánea:

- nuevas regularidades de beligerancia: las huelgas en las fábricas dejan su lugar como forma predominante de protesta en favor de los cortes de ruta;

- cambios estructurales en la raíz de estas regularidades: "desproletarización, retirada del estado y descentralización de servicios de salud y educación";

- interacción entre intereses, organizaciones, oportunidades e identidades;

- continuidades entre protesta y redes clientelares.

Para Auyero, el "contexto estructural" del cambio en el "repertorio de la protesta” son los procesos de "desproletarización”. Aquí se destaca el desempleo estructural a causa de la desindustrialización y la desconexión entre crecimiento del PBI y del empleo, pero fundamentalmente que la desocupación acompañó el crecimiento de la pobreza. Por "retirada y desmantelamiento del estado de bienestar-populista” el autor entiende la degradación de la provisión pública de educación, salud y viviendas. Las privatizaciones, a su vez, revisten un doble aspecto: la retirada del estado de sus funciones básicas y el impacto de las mismas sobre el desempleo (especialmente en comunidades particulares afectadas por el cierre de enclaves productivos tales como talleres ferroviarios o YPF). Por último, la descentralización (la transferencia de servicios educativos y de salud a las provincias) "es de crucial importancia para entender el aumento de la protesta”. Después de estas premisas generales, Auyero describe la desindustrialización en el sentido acotado de desguace de un enclave productivo (en este caso de YPF), en las localidades de Cutral-Co, Plaza Huincul y Mosconi (Salta). Si bien sostiene que la transformación de la empresa en una "industria de enclave" fue "conducida bajo premisas estrictamente capitalistas", destaca que de este modo dejó de ser "la empresa-bienestar alrededor de la cual" giraba la vida de varios pueblos.

¿Cuáles son las reflexiones que nos competen a los efectos de esta reseña? En este caso, se establece una relación lineal entre desindustrialización y crecimiento del desempleo. La desindustrialización ("verificada" localmente) resulta el marco general de un proceso global de "desproletarización” que, a su vez, es

19 TILLY, Charles. "Contentious Repertoires in Great Britain, 1758-1834”. Social Science History. 17, 2, p. 25380, 1993.

20 AUYERO, Javier. "Los cambios en el repertorio de la protesta social en la Argentina". Desarrollo Economico. 42, 166, 2002, pp. 187-210, p. 190. 
la explicación del surgimiento de formas de organización de trabajadores desocupados. En este sentido, el movimiento piquetero resulta al mismo tiempo un efecto de la desindustrialización y una demostración de su importancia. Nuevamente, más allá de discutir la veracidad del impacto de la desindustrialización sobre el desempleo, es interesante destacar la linealidad con que el autor asocia crecimiento del desempleo con una forma específica de organización de la resistencia al mismo como es el movimiento piquetero en Argentina.

En conclusión, hemos visto como la reflexión en el caso de Argentina sobre el impacto del proceso de industrialización y de los procesos de reestructuración capitalista y las formaciones de clase es en términos generales exigua o, más bien, se funda en una serie escueta de supuestos que se deslizan como acuerdos silenciosos entre corrientes teóricas bien divergentes. El contraste de esta situación con los debates que fueron abiertos por E. P. Thompson en la historiografía inglesa es un primer indicio de la necesidad de reflexionar sobre este silencio.

\section{La perspectiva de clase: dos momentos}

El planteo anterior haría lícito preguntarse si “esperar” a E. P. Thompson sería un ejercicio meramente autoreferente, es decir, si estaríamos invocándolo para indagar en un problema cuyo interés se circunscribe solamente a su propia obra. Sostendremos que, muy por el contrario, el problema de comprender la relación entre industrialización y clase y lucha de clases se encuentra en la propia formulación del concepto de clase en Marx. Por lo tanto, mostraremos que la "solución" de E. P. Thompson es una de las más productivas y explícitas (si bien no la única) y que ignorar este problema deviene en simplificaciones o vulgarizaciones del concepto de clase mismo.

Es ya conocido que Marx y Engels comenzaron el Manifiesto del Partido Comunista afirmando que "[t]oda la historia de las sociedades humanas, hasta la actualidad, es la historia de luchas de clases." Esta afirmación, a pesar de su enorme difusión, encierra sin embargo al menos dos problemas interpretativos de interés y nos obliga a algunas explicaciones. Pues, en primer lugar, ¿qué entendemos exactamente por "toda la historia de las sociedades humanas"? Es decir, ¿cómo podemos asumir la existencia universal de clases a lo largo de la historia de la humanidad? Pero aún más, en segundo lugar, ¿cómo dar cuenta al mismo tiempo de la persistencia de la lucha de clases en todo momento histórico? El planteo resulta interesante cuando se formula simultáneamente, puesto que entender a las clases sociales como una ubicación estructural alcanza para dar cuenta de su casi universalidad (largamente más allá del modo de producción capitalista) y resolver la primera parte del dilema. Generalizar mecánicamente la lucha de clases es, en cambio, más conflictivo sin violentar los hechos. Dicho más claramente: no es sencillo universalizar clase y lucha de clases como hacen Marx y Engels en El manifiesto y al mismo tiempo sostener que no existe la lucha de clases sin sujetos políticos antagónicos constituidos como tales y reconociendo el hecho histórico de que las clases sociales no siempre se han constituido como sujetos políticos. 
A nuestro entender, la dificultades planteadas se resuelven no descartando el texto del Manifiesto sino destacando la existencia de dos momentos en la constitución de las clases y consecuentemente dos momentos en la lucha de clases.

Un primer momento del proceso de constitución de las clases consiste en la alteración de las relaciones sociales de producción. En tanto la apropiación de excedente por parte de un grupo de individuos guarda relación con su ubicación determinada en las relaciones sociales de producción, la explotación toma formas específicas en acuerdo a estas relaciones. Para decirlo en una sola frase: las relaciones sociales de producción condicionan la forma de la explotación. En tanto una clase puede entenderse como:

un grupo de personas dentro de una comunidad identificadas por su posición en el sistema global de producción social, definido por sobre todas las cosas, de acuerdo a su relación (primariamente en términos de grados de control) con las condiciones de producción... y por su relación con las otras clases. ${ }^{21}$

Es decir, la clase deviene en "la expresión objetiva de la existencia de la explotación", o más bien la expresión colectiva de una estructura social que tiene imbricadas relaciones de explotación. "La clase (que es esencialmente una relación), es la expresión colectiva de esa explotación."

La constitución de nuevas relaciones sociales de explotación son entonces ese primer momento de constitución de las clases sociales. La acumulación originaria capitalista es el primer momento de conformación de la clase obrera inglesa y de cualquier otro lugar del planeta.

¿Qué hay del conflicto de clases en este primer momento? El conflicto de clases "es esencialmente la relación fundamental entre las clases que involucra explotación y resistencia, pero no necesariamente conciencia de clase, ni actividad colectiva en común". ${ }^{22}$ En otras palabras, a la conformación de intereses contrapuestos se siguen los conflictos entre explotados y explotadores, es decir de conflicto entre clases.

La existencia de explotación (clases) y de conflicto de clases constituyen el "primer momento" de la conformación de las clases. Para evitar ambigüedades y enfatizar que aún la dimensión política consciente no está necesariamente presente es que elegimos usar el vocablo conflicto antes que el de lucha. ${ }^{23}$ Los conflictos de clase pueden expresarse (desplazarse, sublimarse) en las formas políticas más diversas, pero en tanto se originen en conflictos de intereses derivados de la existencia de explotación, es lícito identificarlos como conflictos de clase. En este primer momento la lucha, entendida como enfrentamiento abierto de sujetos antagónicos constituidos políticamente no está necesariamente presente.

Este primer momento de conformación de las clases es aquel momento que Marx y Engels sostienen que conforma "toda la historia de las sociedades humanas hasta la actualidad”. En tanto la historia² hasta la actualidad ha estado signa-

21 STE. CROIX, G. E. M. De. The Class Struggle in the Ancient Greek World: from the archaic age to the Arab conquests. Ithaca, N.Y.: Cornell University Press, 1981.

22 Ibidem.

23 Preferimos esta distinción antes que hablar de "Lucha de clases sin clases" para referirse al conflicto de clases sin "clases para sí", como elige THOMPSON, E. P. "Eighteenth-century English society: class struggle without class?”. Social History. 3, 2, p. 133-65, 1978.

24 Evidentemente la historia de las sociedades sin clases queda relegada en esta frase, no la consideramos menos importante pero excede los límites de este trabajo. 
da por la existencia de relaciones sociales de producción que generan intereses antagónicos y cuyos sujetos pueden entrar en conflicto en torno a estos intereses, es decir, en torno a la forma social de la explotación, es lícito universalizar clases y conflicto de clases. En otras palabras, son generalizables, a lo largo de la historia, las clases y el conflicto "en si".

Pasemos ahora al segundo momento, al momento de constitución de las clases en su dimensión política. Como un proceso diferenciado del primero aparece ya tempranamente en los textos clásicos:

Las condiciones económicas transformaron primero a la masa de la población en trabajadores. La dominación del capital ha creado a esta masa una situación común, intereses comunes. Así pues esta masa es ya una clase con respecto al capital, pero aún no es una clase para sí. En la lucha [... ] esta masa se une, se constituye como clase para sí. Los intereses que defiende se convierten en intereses de clase. Pero la lucha de clase contra clase es una lucha política. ${ }^{25}$

La constitución, entonces, de las clases como “clases para sí” está precedida del conflicto de clases del primer momento. Como acertadamente se insistió desde la nueva izquierda, no puede presuponerse un correlato univoco entre clase, conciencia de clase y clase como sujeto político, es decir no es teórica ni históricamente esperable la "conciencia de clase automática" como implícitamente esperaba el marxismo vulgar estalinista.

Podemos encontrar esta idea de dos momentos en la constitución de las clases ya formulada en El Manifiesto comunista. Así:

El proletariado recorre diversas etapas antes de fortificarse y consolidarse. Pero su lucha contra la burguesía data del instante mismo de su existencia. Al principio son obreros aislados; luego, los de una fábrica; luego, los de todas una rama de trabajo, los que se enfrentan, en una localidad, con el burgués que personalmente los explota. [...] En esta primera etapa, los obreros forman una masa diseminada por todo el país y desunida por la concurrencia. ${ }^{26}$

Aquí, Marx y Engels se refieren al primer momento, donde el conflicto de clases data del momento mismo de la existencia de "clases en sí". En este primer momento, las transformaciones en las relaciones sociales de producción constituyen por si mismas la clase. Así:

Sin embargo, el desarrollo de la industria no sólo nutre las filas del proletariado, sino que las aprieta y concentra; sus fuerzas crecen, y crece también la conciencia de ellas. Y al paso que la maquinaria va borrando las diferencias y categorías en el trabajo y reduciendo los salarios casi en todas partes a un nivel bajísimo y uniforme, van nivelándose también los intereses y las condiciones de vida dentro del proletariado..7

25 MARX, Karl. Miseria de la filosofía.

26 El énfasis está agregado. MARX, K. y ENGELS, F. El Manifiesto comunista.

27 Énfasis agregado. MARX, K. y ENGELS, F. El Manifiesto comunista. 
Si la industrialización es el primer paso en la proletarización creciente de los explotados del modo de producción capitalista en expansión, el momento siguiente es el de un crecimiento de su conciencia. La frase puede llevar a equívocos, pero proponemos entender esa instancia como el segundo momento de constitución de las clases. La conciencia crece como consecuencia de un proletariado más "apretado y concentrado", más homogéneo. Homogeneidad y conflicto son, en El Manifiesto, los dos ingredientes fundamentales del segundo momento, de la conciencia de clase y la lucha abierta.

Un sin número de conflictos puede interpretarse entonces como conflictos en torno a intereses contrapuestos en la apropiación de excedente, es decir, como conflictos de clase, aún cuando sus propios protagonistas no lo entiendan de ese mismo modo. ${ }^{28}$ La comprensión de los protagonistas, o incluso la forma de organización de los mismos, puede articularse en torno a una identidad religiosa, racial o corporativa. También es cierto lo contrario: organizaciones autodenominadas clasistas (sindicatos por ejemplo) pueden involucrarse en objetivos o luchas que no guarden necesariamente relación con sus intereses de clase.

Los enfrentamientos, entonces, toman relevancia no por sus logros sino por el tipo de organizaciones que constituyen:

Los obreros empiezan a coaligarse contra los burgueses, se asocian y unen para la defensa de sus salarios. Crean organizaciones permanentes para pertrecharse en previsión de posibles batallas. Los obreros arrancan algún triunfo que otro, pero transitorio siempre. El verdadero objetivo de estas luchas no es conseguir un resultado inmediato, sino ir extendiendo y consolidando la unión obrera. ${ }^{29}$

Este segundo momento tiene una entidad analítica privilegiada por su importancia política. Esta perspectiva no es menos importante, más bien por el contrario, es decisiva para la dinámica de las luchas. Así:

El movimiento político de la clase obrera tiene como último objetivo, claro está, la conquista del poder político para la clase obrera y a este fin es necesario, naturalmente, que la organización previa de la clase obrera, nacida en su propia lucha económica, haya alcanzado cierto grado de desarrollo.

Pero, por otra parte, todo movimiento en el que la clase obrera actúa como clase contra las clases dominantes y trata de forzarlas "presionando desde fuera", es un movimiento político. Por ejemplo, la tentativa de obligar, mediante huelgas, a capitalistas aislados a reducir la jornada de trabajo en determinada fábrica o rama de la industria, es un movimiento puramente económico; por el contrario, el movimiento con vistas a obligar a que se decrete la ley de la jornada de ocho horas etc., es un movimiento político. Así pues, de los movimientos económicos separados de los obreros nace en todas partes un movimiento político, es decir, un movimiento de la clase, cuyo objeto es que se dé satisfacción a sus intereses en forma general, es decir, en forma que sea compulsoria para toda la sociedad. $\mathrm{Si}$ bien es cierto que estos movimientos presuponen cierta organización previa, no es menos cierto que representan un medio para desarrollar esta organización. ${ }^{30}$

Es interesante señalar que en la concepción de Marx la conformación de un movimiento político no es cualquier forma de organización de la clase obrera. Un

28 Podría hablarse de conflictos de clase como la mirada "etic" (desde el punto de vista del observador) y la lucha de clases entraría en la atención de una perspectiva "emic" (la aproximación de los sujetos).

29 MARX, K. y ENGELS, F. El manifiesto comunista.

30 Carta de Marx a Friedrich Bolte (23 de noviembre de 1871). 
movimiento político de la clase obrera no lo constituye "la tentativa de obligar mediante huelgas" aisladas a reducir la jornada sino que se conforma cuando intenta "obligar a que se decrete la ley de la jornada de 8 horas".

En este recorrido falta advertir contra un sesgo que los términos "primer y segundo momento" podrían implicar falazmente. Los dos "momentos" no son consecutivos, ni guardan una relación unidireccional. Es decir, la historia de la constitución de las clases no sigue un primer momento de transformación de las relaciones sociales de producción y luego otro de organización política de las clases. No solo el segundo momento puede no suceder, sino que el primer momento "vuelve a suceder", es decir que se da un proceso reiterado de transformación. A su vez, ambos procesos se ven realimentados y condicionados mutuamente: por ejemplo, las condiciones "objetivas" de explotación cambian como resultado de la respuesta capitalista a la resistencia de la clase obrera, es decir, a la resistencia de sujetos políticos constituidos en un "segundo momento" anterior. La reestructuración capitalista es, por ejemplo, un intento de romper formas de estructuración política de la clase obrera mediante la transformación de las condiciones de la producción.

También, es lícito cuestionarse cuál fue la aproximación de Marx mismo al problema de la dialéctica entre ambos momentos. Evidentemente, en tanto no podemos hablar de una reflexión explícita sistemática del concepto de clase en Marx, tampoco es posible encontrar este desarrollo en su obra. Es posible, sí, mencionar al menos tres instancias donde esta reflexión se asoma. En primer lugar, en las consideraciones sobre la transformación de los procesos de trabajo en la manufactura y la gran industria y sus efectos diversos sobre la organización política de trabajadores y trabajadoras. Marx ve dos tendencias contradictorias: por un lado, la "mutilación" (el obrero colectivo enfrentado al obrero individual) y, por otro, la "homogeneización" de las condiciones de trabajo. Además, intuye que en tanto que fuerza de trabajo, el "obrero colectivo" del taller construye lazos técnicos que no serán neutros a la hora de conformar organizaciones políticas. También, en las reflexiones sobre las estrategias capitalistas de aumento de la tasa de plusvalor, plusvalor absoluto y relativo, Marx se figura que estas dos estrategias del capital condicionan formas distintas de organización y respuesta de parte de los trabajadores (un tipo de resistencia es posible en el contexto de subsunción formal y otra en un contexto de subsunción real). En tercer lugar, todos los escritos de Marx sobre la jornada laboral resultan claves para indagar en la constitución de la clase obrera como sujeto político. Marx sostiene que la ley de intercambio mercantil no ve en la disputa sobre el uso de la mercancía "fuerza de trabajo" (la extensión de la jornada) más que "derecho contra derecho", y por tanto una cuestión que se dirime según la relación de fuerzas de ambas clases. Entonces, esta disputa se resuelve en el plano político, donde la clase obrera puede enfrentarse al Estado en tanto que clase contra la clase burguesa.

En suma, hemos ejemplificado como la concepción de clase social desde las tempranas formulaciones de Marx y Engels presupone la existencia de dos momentos diferenciados. A su vez, encontramos algunos elementos de teorización sobre las formas en que se estructura una relación entre ambos. La industrialización es una fuente de homogeneización de las condiciones de vida de los proletarios, unificando por un lado salarios, condiciones de trabajo y calificación (descalificando), disolviendo la existencia de otras clases (la "pequeña propiedad artesanal") y hasta internacionalizándola. ${ }^{31}$ La creciente homogeneidad de estas condiciones

31 "Ya el propio desarrollo de la burguesía el libre cambio, el mercado mundial, la uniformidad reinante en la producción industrial, con las condiciones de vida que engendra, se encargan de borrar más y más las diferencias y antagonismos nacionales." Marx y Engels, El manifiesto comunista. 
se asume como el camino hacia el crecimiento de la conciencia de clase, hacia una fortaleza que procede de la mayor sencillez en reconocerse iguales a otros. Y a su vez, la clase obrera se constituye a si misma en la lucha (en el segundo momento), pero no cualquier lucha sino aquella contra el Estado (por conseguir una ley), en tanto se enfrentan trabajadoras y trabajadores constituidos como clase contra capitalistas en igual condición (constituidos en el Estado como una clase). ${ }^{32}$

\title{
El concepto de "experiencia" y su recepción en Argentina
}

La Formación de la clase obrera en Inglaterra es un libro excepcional en un sin número de sentidos. Los cincuenta años que nos separan de la producción la han convertido en un clásico y en una forma apasionante de texto cada vez más difícil de ser producido en un contexto académico, tanto por su narrativa, su lenguaje accesible, como por su implacable irreverencia. ${ }^{33}$

Es también conocido que en su prólogo inaugura una definición de clase como proceso y que propone el concepto de experiencia en el centro de la articulación, determinada, de este proceso:

\begin{abstract}
la clase sucede cuando algunas personas, como resultado de experiencias comunes (compartidas o heredadas), sienten y articulan la identidad de sus intereses como entre si, y como contra otras personas cuyos intereses son distintos de (y usualmente opuestos a) los suyos. La experiencia de clase esta mayormente determinada por las relaciones productivas en las que las personas nacen o entran involuntariamente. ${ }^{34}$
\end{abstract}

Lo cierto es que la variada recepción de La Formación de la clase obrera en Inglaterra ha enfatizado hasta el bostezo su definición de clase como proceso activo y relación histórica como una forma de superar la concepción (estalinista, pero no únicamente) de clase como ubicación estructural. Seguidores vulgares y críticos por igual han entendido que esta concepción thompsoniana de clase convertía a los estudios sobre la clase obrera en un ejercicio ateórico, en un empiricismo que no discriminaba ya entre fenómenos para rescatar del olvido cualquier tipo de contribución heroica a la construcción de un conglomerado popular. ${ }^{35}$ Así, Nairn sostenía que la historia desde abajo se convirtió en una suerte de poema épico, sin principio ni fin, de los logros populares y radicales. O, Perry Anderson, que "el resultado es una definición de clase que es demasiado voluntarista y subjetivista". ${ }^{36}$

Políticamente, por otra parte, se acusaba a Thompson de encuadrarse dentro de un "socialismo populista" romántico. ${ }^{37}$ En un sentido, como señala Ellen Meiksins

32 Para este argumento ver por ejemplo CLEAVER, Harry. Una Lectura Politica de El Capital. Mexico: Fondo de Cultura Económica, 1985.

33 Un argumento similar ha desarrollado recientemente CAHILL, Rowan. "Would The Making of the English Working Class get made today?" En: http://overland.org.au/2013/og/would-the-making-of-the-englishworking-class-get-made-today/

34 THOMPSON, E. P. The Making of the English Working Class. NY: Vintage, 1966.

35 Como ejemplo de los primeros, además de buena parte de la recepción en Argentina, podemos citar al grupo History Workshop y para alguna de estas críticas NAIRN, Tom. The Break-up of Britain: crisis and neo-nationalism. Melbourne: Common Ground, 2003, especialmente pp. 291 y ss.

36 ANDERSON, Perry. Arguments Within English Marxism. London: NLB, 1980, p. 40.

37 WOOD, Ellen Meiksins. "The Politics of Theory and the Concept of Class: E. P. Thompson and his Critics". Studies in Political Economy. 9, o ,1982, p. 46. 
Wood, tanto la recepción como la crítica que entendieron que para Thompson se pueden olvidar las determinaciones objetivas o las condiciones estructurales de la clase y que la noción de "experiencia" es en definitiva puramente contingente (y que no hay por tanto clase sin conciencia de clase, o que es válido el romanticismo populista según el cual cualquier expresión popular de resistencia es clasista) y, formulado de esta manera, en ambos casos, coincidimos en afirmar que eso "es simple y sencillamente no entender su argumento"..$^{8}$ El problema central que Thompson intenta estudiar es el que hemos llamado la relación entre el primer y el segundo momento en la lucha de clases. Es decir

no es un problema de definir las clases "en referencia" a la conciencia de clase antes que a las relaciones de producción, sino más bien de investigar los procesos por los cuales las relaciones de clase dan lugar a formaciones de clase y a la "disposición para comportarse como tal".39

El énfasis de E. P. Thompson en las formaciones es un esfuerzo por evitar que la proposición "las clases se constituyen por los modos de producción" se trague la pregunta de cómo esas clases constituidas objetivamente (ese primer momento) da lugar a formaciones de clase (el segundo momento). Una mirada atenta a este problema, señala que:

La lucha de clases, por lo tanto, precede a la clase, tanto en el sentido que la formaciones de clases presuponen una experiencia del conflicto y la lucha que nacen de las relaciones de producción, cuanto en el sentido de que hay conflictos y luchas estructurados "en formas de clase" incluso en formaciones sociales que todavía no tienen formaciones de clase con conciencia de clase. ${ }^{40}$

Por fuera de la confusión que introducen los términos, la lectura de Meiksins Woods es enteramente coincidente con lo dicho hasta aquí: el primer momento (clase en si y conflicto de clase) precede al segundo momento de formación de las clases como sujetos políticos.

En este punto debemos destacar que es la idea de "experiencia" el principal intento por sistematizar las formas de articulación de respuestas culturales, sociales y colectivas a la explotación. En este sentido Thompson propone un concepto determinado estructuralmente por la dimensión de objetiva de clase, determinado estructuralmente por las posiciones relativas en las relaciones sociales de producción pero al mismo tiempo articulado históricamente. La "experiencia" es aquella la herramienta teórica con que el autor intenta pensar la dialéctica entre primer y segundo momento en la constitución de las clases. En palabras de Thompson, la experiencia es "el término medio necesario entre el ser social y la conciencia social". ${ }^{41}$

Si este era el legado fundamental de la obra clásica de E. P. Thompson y cincuenta años después encontramos el silencio que venimos señalando en este trabajo, es lícito preguntarse, más no sea brevemente, qué hizo posible una recepción tan idiosincrática. La respuesta reside en las condiciones históricas en que se introdujo E. P. Thompson en Argentina.

38 WOOD, op. cit., p.48.

39 Ibidem, ibidem.

40 Ibidem, p.51.

41 THOMPSON, E. P. Miseria de la Teoría. Barcelona: Grijalbo, 1981, p. 160. 
En un contexto político y social bien distinto de aquel en que la obra fue escrita (el ascenso de un ciclo de luchas mundiales en los años '60), el de Argentina en los años ' 80 nucleaba un conjunto de autores distanciados del activismo político, progresivamente del marxismo y crecientemente comprometidos con la construcción de un orden democrático. Thompson servía para criticar la idea de una "determinación automática" entre estructura y superestructura y para abrir la agenda a los estudios culturales, las condiciones de vida de trabajadoras y trabajadores y otros aspectos de la vida urbana. ${ }^{42}$ La misma noción de clase obrera para algunos resultó un obstáculo y propusieron su reemplazo por el concepto de "sectores populares". 43

El concepto de experiencia de Thompson no fue ignorado, sino, por el contrario, entendido como un intento "de dar prioridad a las determinaciones subjetivas en el proceso de conformación de la clase obrera" ${ }^{44}$, es decir, tal como mencionaba antes Meiksins Wood, en su más pura dimensión contingente. Viotti da Costa señalaba este mismo hecho, notando que la preocupación por el concepto de experiencia era controvertida "en tanto experiencia es una palabra esquiva". 45

En suma, la liberación de la prisión estructuralista o estalinista hizo olvidar en esta recepción el núcleo fundamental de las preocupaciones de E. P. Thompson. Si bien las condiciones históricas de su recepción original explican parcialmente este hecho, resta preguntarnos por qué esta reflexión aún sigue vacante.

\section{Conclusiones}

Hemos recorrido brevemente un problema cuya dimensión es auto evidente. Tanto la profundidad de las transformaciones ocurridas en el último cuarto de siglo como los cambios simultáneos en las formas de lucha de la clase obrera, y, fundamentalmente, el empeoramiento de su condición general, nos obliga a reflexionar y debatir sobre la dialéctica entre uno y otro fenómeno.

Si hemos encontrado extensos silencios sobre este problema en el caso de Argentina, el trabajo ha mostrado a su vez que esta reflexión se encuentra tanto en las preocupaciones de los clásicos (Marx en particular) y en el centro de la renovación y los desafíos que E. P. Thompson planteara en La Formación de la clase obrera en Inglaterra cincuenta años atrás.

La urgencia de la pregunta y las falencias de un problema de mucha más profundidad que la formulada condicionan, en última instancia, la posibilidad de hacer inteligible la lucha de clases, de indagar sus límites estructurales.

Recebido em 16/09/2013

Aprovado em 05/12/2013

42 POY, Lucas. "The making of labor history: tracing the influence of E.P.Thompson in Argentina”. The Global E. P. Thompson: Reflections on the Making of the English Working Class after Fifty Years. Mimeo. Texto presentado en The Global E. P. Thompson: Reflections on the Making of the English Working Class after Fifty Years, Harvard University, Massachusetts, 2013. También NIETO, Agustín. "Los usos de E. P. Thompson, un itinerario posible de la recepción de su obra en la historiografía argentina”. Mimeo. Texto presentado en Qué hacer con E. P. Thompson? Universidad Nacional de Quilmes, 2013.

43 ROMERO, Luis Alberto. "Los sectores populares urbanos como sujetos históricos". Proposiciones. 19, 1990; ROMERO, Luis Alberto. "Los sectores populares en las ciudades latinoamericanas del siglo XIX: la cuestión de la identidad”. Desarrollo económico. pp. 201-22, 1987.

44 SORGENTINI, Hernán Antonio. "La recuperación de la experiencia histórica: Un comentario sobre E. P. Thompson”. Sociohistórica. 0, 7, 1999, p. 65.

45 VIOTTI DA COSTA, Emilia. "Experience versus Structures: new tendencies in the History of Labor and the Working Class in Latin America: What do we gain? What do we loose?" International Labor and WorkingClass History. 36, 1989, pp. 3-24, 8. 